\title{
O Peso da Imprensa na Balança Eleitoral. Efeitos, estratégias e parâmetros para o exame da gravidade das circunstâncias em hipóteses de uso indevido dos meios de comunicação social
}

\author{
The Weight of the Press in the Electoral Scale. Effects, strategies, and parameters for the \\ examination of severity of the circumstances in cases of improper use of the social communication
}

\section{Frederico Franco Alvim}

\begin{abstract}
Segue de tudo o que precede que a vontade geral é sempre reta e tende à utilidade pública, mas não que as deliberações do povo tenham sempre a mesma retidão. Quer-se sempre o bem, mas nem sempre se sabe onde o bem está. Nunca se corrompe o povo, porém frequentemente se lhe engana, e somente então é quando o povo parece querer o mal. (J. J. Rousseau)
\end{abstract}

Resumo: O presente trabalho contempla um estudo de questões relativas ao fenômeno do uso indevido dos meios de comunicação social, direcionado à produção de uma aproximação teórica sobre a origem e os fundamentos do poder de persuasão pública incorporado pela mídia, os reflexos da cobertura jornalística sobre o comportamento eleitoral e as estratégias que evidenciam a presença de parcialidade nas atividades dos veículos da mídia. Cuida ainda de oferecer parâmetros válidos para a aferição da gravidade de suas circunstâncias, requisito indispensável para a prolação de decisões de cassação seguras em sede de ações eleitorais em que se discutem casos de abuso de poder.

Palavras-chave: Eleições. Legitimidade. Imprensa. Poder.

\begin{abstract}
This paper intent to face questions about malpractices held in media coverage during elections. The study approaches some particular issues: the persuasion power detained by press corporations; effects of media coverage in electoral behavior; and favoritism strategies in information activities. This paper also provide parameters for jurisdictional evaluations about the heaviness of such lacks.
\end{abstract}

Keywords: Elections. Legitimacy. Press. Power.

Artigo recebido em 30 dez. 2016 e aprovado em 12 abr. 2017. 


\section{Introdução}

No cenário moderno as eleições constituem elemento crucial para o reconhecimento de regimes democráticos. Malgrado não resolvam em definitivo o problema da legitimação ${ }^{1}$, os processos de escolha instrumentalizam a formação de governos e parlamentos qualificados pelo aceite popular pavimentando o necessário vínculo entre a vontade do povo soberano e o instituto da representação.

Essa função sistemática de amparo, contudo, depende do correto progresso de suas fórmulas e mecanismos. Os desvios eleitorais tendem a atrair percepções negativas dos diversos atores políticos e a dessorar o comprometimento com os seus resultados, arriscando assim a crença na validade da ordem e a estabilidade do plano político. Déficits nos níveis de integridade eleitoral empiricamente acarretam problemas reais: diminuem a confiança nas autoridades eleitas, incrementam os níveis de abstenção, disparam protestos e exacerbam conflitos (NORRIS, 2014, p. 6) ${ }^{2}$. Como sublinha Espiell (apud FREITAS, 2007, p. 52), se o ato eleitoral não se desenvolve consoante normas rígidas, dirigidas a assegurar a pureza e a verdade da vontade que nele se expressa, a eleição não tem razão de ser, ela nada significa.

Entre a ampla gama de ilícitos eleitorais, destacam-se as variantes do abuso de poder. $\mathrm{O}$ presente trabalho visa contribuir para o estado de conhecimento de questões afetas a uma de suas formas típicas, o abuso de poder midiático, decorrente da laboração nociva dos meios massivos de comunicação. Como desígnios específicos, exsurgem as tarefas de demarcação

\footnotetext{
${ }^{1}$ Em sua origem, a noção de legitimidade se apresenta como uma crença positiva no valor das instituições democráticas, derivada da realização de eleições limpas e periódicas; por oposição, no exercício do poder a legitimidade é posta em teste e expõe-se a riscos, em casos de escândalos, desvios ou crises de governabilidade, efetividade ou eficácia, como decorrência de uma avaliação racional feita pelo povo, em um jogo de vigilância sobre a adequação dos meios e dos fins. (MENÉNDEZ, 2009, p. 58).

${ }^{2}$ Como explica Kofi Annan, ex-Secretário-Geral da ONU, no prólogo do Informe da Comissão Global sobre Eleições, Democracia e Segurança (2012): "Cuando el electorado cree que las elecciones fueron libres y justas, éstas pueden actuar como potentes catalizadores para mejorar la gobernabilidad e incrementar la seguridad y el desarrollo bumano. Sin embargo, cuando las elecciones carecen de credibilidad, los ciudadanos no disponen de recursos que permitan un cambio político pacifico. En tales casos, aumenta el riesgo de que surjan conflictos; la corrupción, la intimidación y el fraude proliferan de manera incontrolada; y el sistema político en su conjunto comienza a descomponerse lentamente desde su propio interior".
} 
conceitual, descrição elucidativa, avaliação hipotética de efeitos, e mensuração de circunstâncias concretas.

A metodologia empregada concerne à vertente jurídico-sociológica, buscando uma compreensão do panorama normativo em suas relações com a realidade social. Quanto à técnica, vale-se da análise de literatura especializada, de modo a recrudescer o trabalho jurídico com aportes variados, oriundos da Ciência Política e da Teoria da Comunicação. Objetiva-se, afinal, aprimorar o estado científico da questão selecionada como tema central da investigação.

\section{Poder: uma Aproximação Teórica}

Poder é um vocábulo polissêmico. O uso em diferentes contextos impele a um trabalho de precisão. $\mathrm{Na}$ teoria política o fenômeno tem sido abordado, principalmente, em três perspectivas. Pela ótica institucionalista a palavra diz respeito aos poderes públicos, sendo usada para designar a força incorporada pelo Estado: falar de poder, nessa trilha, é falar de governantes ou de um ente coletivo transcendente e oposto à sociedade civil (HERMET et al, 2014, p. 235). Em noção substantiva o poder é visto como "algo suscetível de posse", isto é, como "um bem ou uma prerrogativa que se pode possuir” (SÁNCHEZ, 2012, p. 44). Nesse sentido, o poder é entendido como um objeto: um instrumento que serve ao homem para alcançar uma meta desejada (CAMPOS, 2012, p. 30) ${ }^{3}$.

Prevalece, porém, uma terceira teoria, denominada relacional. Por esse prisma, o poder opera nas relações entre sujeitos: existe e cobra sentido exclusivamente no seio de interações humanas. Segundo Sartori (2009, p. 20):

\footnotetext{
${ }^{3}$ A tese substantiva recebe muitas críticas. Stoppino (1993, p. 934) argumenta que em perspectivas substanciais, o poder é entendido "[...] como um objeto ou uma substância que se guarda num recipiente. Contudo, não existe Poder se não existe, ao lado do indivíduo ou grupo que o exerce, outro indivíduo ou grupo que é induzido a comportar-se tal como aquele deseja. Sem dúvida [...] o Poder pode ser exercido por meio de instrumentos ou coisas. Se tenho dinheiro, posso induzir alguém a adotar um certo comportamento que eu desejo, a troco de recompensa monetária. Mas, se me encontro só ou se o outro não está disposto a comportar-se dessa maneira por nenhuma soma de dinheiro, o meu Poder se desvanece. Isto demonstra que o meu Poder não reside numa coisa (no dinheiro, no caso), mas no fato de que existe um outro e de que este é levado por mim a comportar-se de acordo com os meus desejos. O Poder social não é uma coisa ou sua posse: é uma relação entre pessoas".
}

Resenha Eleitoral (Florianópolis), v. 20, n. 2, p. 33-59, ago./de\%: 2016 
El poder es una relación: un individuo tiene poder sobre outro porque le oliga a bacer lo que de otra forma no haría. Robinson Crusoé, en la isla donde naufragó, mientras esté solo no tiene ningún poder, únicamente lo adquiere cuando llega Viernes ${ }^{4}$.

Ao Direito Eleitoral interessa o poder como fenômeno das relações interpessoais de maneira que o sentido que se lhe confere peja sempre um feitio social. Entende-se o poder como o faz Stoppino (2009, p. 933), isto é, como a "capacidade do homem em determinar o comportamento do homem", o que o coloca não apenas como sujeito, mas também como objeto do poder.

A dicotomia conceitual existente entre o poder como prerrogativa (sentido comum) e o poder como fenômeno de ingerência no comportamento alheio (sentido social) não impede, porém, uma consideração conjunta, na tarefa de desvendar a sua natureza. Fernández Ruiz (2010, p. 11), ao discorrer sobre a índole do poder, assevera que se trata, sim, de uma prerrogativa, entretanto de uma prerrogativa especial, a qual se relaciona com a capacidade de influenciar alguém com quem se trava alguma espécie de interação. O poder se apresenta como capacidade de fazer algo, mas obviamente não se esgota nessa capacidade porque, mais do que isso, implica uma nota específica: a capacidade de impor a alguém a própria vontade baseando-se na possibilidade que se tenha de aplicar efeitos benéficos ou prejudiciais aos demais, isto é, de punir ou recompensar um comportamento alheio.

Sustentando, pois, o argumento de que o fenômeno representa uma substância potencialmente aplicada em uma relação social, o aquele autor toma o poder como uma energia disponível para uma conduta, energia essa que, para atuar, necessita de um sujeito (depositário do poder), de um objeto (o seu destinatário), e de um fundamento (a vontade que se impõe). Tendo fixado os seus requisitos, concebe o poder como a capacidade de um indivíduo ou grupo, gerada por sua libido dominandi de conferir efeitos agradáveis ou desagradáveis à conduta de outro indivíduo ou grupo, com o fim

\footnotetext{
${ }^{4}$ Em português: “O poder é uma relação: o indivíduo tem poder sobre outro porque o obriga a fazer o que de outra forma não faria. Robinson Crusoé, na ilha onde naufragou, enquanto esteja sozinho não tem nenhum poder, unicamente o adquire quando chega Sexta-feira".
} 
de impor-lhe a sua vontade para lograr um determinado comportamento individual ou coletivo. (FERNÁNDEZ RUIZ, 2010, p. 13).

Cuida-se de proposta assaz semelhante à clássica definição de Weber (1920, p. 43), que descreve o poder como "[...] a probabilidade de impor a própria vontade, dentro de uma relação social, ainda contra toda resistência e qualquer que seja o fundamento dessa probabilidade”. Em linha análoga, Gaitán (2005) o define como uma relação humana de subordinação na qual, a despeito de obstáculos e oposições porventura apresentadas, prevalece a vontade dos que mandam sobre à dos que obedecem, implicando em dois elementos essenciais - mando e obediência - e, consequentemente, a existência daqueles que mandam e daqueles que obedecem. Em suas palavras, o poder é simplesmente uma capacidade para se fazer obedecer.

\section{O Abuso de Poder nas Eleições}

Nos termos de Vilas (2013) toda relação de poder apresenta duas características básicas: efetividade e intencionalidade. A efetividade existe porque o poder cobra existência em seus próprios efeitos, isto é, materializa-se apenas quando lograda a obediência buscada. Um poder que manda sem encontrar cumprimento, a rigor, é apenas um propósito frustrado (FERNÁNDEZ RUIZ, 2010, p. 12). A intencionalidade se apresenta porque à relação de poder invariavelmente amarra-se um propósito, visto encontrar-se sempre orientada à obtenção de uma resposta produzida pelo sujeito sobre o qual o poder se exerce. Todo poder, assim, carrega uma intencionalidade finalista, haja vista que sua força existe e atua com e para uma finalidade específica (CAMPOS, 1985, p. 31).

No plano eleitoral, a intenção em seu emprego é bastante clara: o poder serve ao acúmulo de votos, capital necessário para a vitória no certame. Frequentemente o sujeito apoderado vale-se de ações destinadas a um objetivo positivo (determinar o vencedor da contenda); não é impossível, porém, que efeitos de poder sejam utilizados com o fito de obstar o êxito de desafetos ou adversários, quando então, com feição negativa, serão aplicados para sabotar uma fórmula política específica.

Como recurso didático, é possível adequar a proposta de Fernández Ruiz (2010) propondo um esquema ilustrativo básico sobre a operabilidade do abuso nas eleições. Considerados, então, os elementos que caracterizam as relações de ingerência, o jogo de poder compõe-se dos seguintes 
elementos: como sujeito, pessoas ou grupos que ostentam alguma espécie de hegemonia social (candidatos, coordenadores de campanha, cabos eleitorais, partidos políticos, conglomerados econômicos, veículos da mídia, ministros religiosos, etc.), e que se propõem a empregá-la na fase de campanha em favor (o que é mais frequente) ou em detrimento (o que é mais raro) de uma determinada candidatura; como objeto, o corpo de eleitores ou, mais propriamente, cada cidadão que o compõe, visto que o voto é individualizado e o que o poder, nessa cena, opera em plataformas microssociais; e como fundamento (vontade que se pretende impor) o desejo de solapar a autonomia da vontade para dirigir o sentido do voto. Esse impulso atua mediante a projeção de um resultado absorvido pelo destinatário, a partir do efetivo emprego das prerrogativas que o sujeito ativo incorpora em função da qualidade do poder que ostenta.

O emprego do abuso de poder é uma realidade nefasta no cenário eleitoral: afeta a liberdade da escolha do eleitor e mina violentamente a igualdade de oportunidades entre os candidatos, condicionando o resultado do certame e, assim, comprometendo o nível de integridade eleitoral. A ofensa a esses valores é levada em conta por Bim (2003, p. 46), que as utiliza para forjar um conceito; em suas palavras, o abuso de poder nas eleições constitui "um complexo de atos que desvirtuam a vontade do eleitor, violando o princípio da igualdade entre os concorrentes do processo eleitoral e o da liberdade de voto, que norteiam o Estado democrático de direito”.

Na mesma linha, Gomes (2009) é categórico ao ressaltar a sua nocividade, dizendo que o pleito no qual o abuso se instala resulta necessariamente corrompido, na medida em que impede que as urnas reflitam a vontade genuína do eleitor. Em sua visão isso contribui para a formação de uma representação política "inautêntica e mendaz".

A campanha eleitoral, compreendida como um conjunto de atividades desenvolvido com o propósito de captação de votos, tanto no aspecto financeiro como nos aspectos político e ideológico, deve ser conduzida de acordo com os limites previstos no ordenamento, e esses limites hão de plasmar escolhas legislativas que resguardem um mínimo de competitividade, sob pena de comprometer a autenticidade do processo de escolha.

O uso desmedido do poder - em qualquer de suas formas - deve ser impedido no plano fático, a partir de soluções desenhadas no campo normativo e implementadas pela atividade jurisdicional. No cenário brasileiro, o ordenamento eleitoral proscreve o abuso de poder em três diferen- 
tes formas ${ }^{5}$ : abuso de poder político; abuso de poder econômico; e abuso de poder midiático (ou uso indevido dos meios de comunicação), tema desenvolvido nos próximos tópicos.

\section{O Uso Indevido dos Meios de Comunicação}

\subsection{Conceito e Mecânica}

Os media exercem papel fundamental nas sociedades modernas, porquanto atuam como motores da difusão de informação e conhecimento. Modernamente o acesso à informação é considerado essencial para a qualificação das democracias, haja vista que o exercício satisfatório das prerrogativas políticas só pode ocorrer com base em decisões sustentadas por uma dose suficiente de (boa) informação. (FIGUEIREDO, 2013, p. 212).

O ponto é que o direito à informação adequada esbarra na realidade. O correto processo de formação do convencimento político claramente supõe o acesso a informações neutras e, nessa quadra, é imperioso anotar que a existência de objetividade é bastante questionada na área comunicacional. ${ }^{6}$

Na prática, os veículos de comunicação se apartam de sua missão, usando da força de que dispõem para agendar a audiência, selecionando pautas, imprimindo ou retirando ênfase às notícias, matizando acontecimentos de modo a promover interesses setorizados, ocasionando prejuízos ao sistema político em que se inserem ${ }^{7}$. Há, no caso dos meios, um patente

\footnotetext{
${ }^{5}$ Cuida-se de uma opção legislativa extremamente criticável. O poder constitui, na verdade, uma realidade amorfa, manifestável pela via de infindáveis fontes. Como coloca José Pablo Feinmann (2013, p. 164): "El Poder tiene mil tentáculos. Se expresa en mil situaciones. Pareciera que no existe sobre este planeta un solo ser que no esté bajo el señorio de alguien. El señorio es una escalera interminable". Para o estudo do polimorfismo e das formas atípicas de abuso de poder (abuso de poder religioso, abuso de poder coercitivo), vide ALVIM, Frederico Franco. "Curso de Direito Eleitoral”. 2 $2^{\underline{a}}$ ed. Curitiba: Juruá, 2016.

${ }^{6}$ Barros Filho (2003, p. 30-34) menciona que os códigos de ética e os ordenamentos a respeito da imprensa veem na objetividade uma garantia de proteção social, mas que no plano fático o comportamento da mídia caracteriza-se por uma constante falta de neutralidade informativa. Por tal motivo, comenta serem cada vez mais numerosos os especialistas a defender que no campo da comunicação a objetividade é mesmo impossível, apresentando-se apenas como um conceito típico ideal.

7 "Aos meios de comunicação cabe, hoje em dia, a quota-parte mais importante no fornecimento de informações e na articulação da opinião pública. Já a selecção e apresentação das informações desempenham um papel importante na formação da opinião pública: 
dissenso entre ser e dever-ser, e a distância que os separa denota a diferença entre enxergá-los como fatores de desprestígio ou de recrudescimento do regime democrático. Essa lógica dual é bem explicada por Lamizet (apud MIÈGE, 2009, p. 10):

O paradoxo das mídias e das formas e estratégias de comunicação mediatizada é exatamente esse: ao mesmo tempo, as mídias são lugares não democráticos de comunicação e informação pelas formas de poder que se instauram no espaço público e pelas tendências ao monopólio que caracterizam a realidade da comunicação, e garantem a existência de lugares públicos de expressão e de informação, condição necessária do exercício de uma forma democrática de sociabilidade política.

No esquema de Bobbio (2000), a imprensa incorpora um poder ideológico na medida em que produz informações massificáveis capazes de sugestionar a opinião pública, induzindo o corpo social a que reaja de uma maneira preconcebida. Uriarte (2010) acresce que aquele poder existe porque as ideias possuem uma enorme capacidade para influenciar os cidadãos, visto que os comportamentos econômicos ou políticos explicam-se, em boa medida, com apoio em valores difundidos que se tornam predominantes. Ademais, como observado por Lippmann (2008, p. 28-30), "em qualquer sociedade que não esteja completamente voltada a si mesma [...] e nem tão pequena que todos possam saber tudo o que se passa, as ideias dizem respeito a eventos que estão fora da vista e do alcance". Os comportamentos respondem não aos fatos tal como ocorrem, mas tal como relatados, o que faz com que as pessoas reajam a "pseudoambientes".

O poder midiático opera de modo realmente simples, a partir da premissa de que o processo de compreensão (assimilação) depende da co-

na era da imprensa de massas e da televisão, o indivíduo recebe os seus conhecimentos sobre o mundo, numa parte essencial, por meio dessas instituições. [...] Através da seleção, classificação e apresentação das suas informações, os meios de comunicação conseguem, portanto, marcar em escala considerável os conhecimentos sobre o mundo e seus destinatários. Efectivamente, a oferta de informações é já precedida de vários processos seletivos e tentativas de classificação mental por parte dos meios de comunicação social: já a parcialidade inevitável de repórter e do observador imediato conduz a uma selecção e a um realce dos factos relatados. Segue-se uma seleção das informações primeiro pelas agências noticiosas, depois pelas redações, que funcionam desse modo como guardas de comporta do fluxo de informação. [...] A ideia que a população faz dos acontecimentos do mundo é determinada em grande medida por esta selecção e tratamento das informações. Deste modo também se confere eficácia aos modos de pensar, às ideologias e as intenções dos modernos 'produtores de opinião e de visões de mundo."' (Zippelius, 2016, p. 411). 
municação (BARROS FILHO, 2003, p. 61). Fayt (2009) explica que, pelos efeitos, comunicar é sinônimo de influir na mente humana, utilizá-la com o fim de obter controle ou adesão, assim, como dominar é influir, influi-se na mente para dominar a vontade individual.

A serviço dessa "orientação negativa da personalidade humana" encontram-se os meios de comunicação, frente aos quais o homem vai perdendo toda a possibilidade de pensar por si mesmo ${ }^{8}$. Esses elementos intervêm na elaboração das estruturas mentais e arrebatam do indivíduo o direito à liberdade na formação da própria convicção.

No contexto eleitoral, o abuso do poder midiático traduz-se na utilização da imensa capacidade de influência que os órgãos de produção de informação possuem como fator de quebra da equidade entre os competidores e de menoscabo das condições objetivas de liberdade que devem estar presentes no desenvolvimento do processo eleitoral (MUÑOZ, 2007, p. 38). Refere-se, então, ao uso incisivo dos veículos de imprensa como instrumentos de condução dirigista do eleitorado, ocultando a finalidade de promoção ou descredenciamento de alternativas políticas em medida suficiente a comprometer a plena lisura de todo o processo.

\subsection{Estratégias}

A abordagem midiática desigual pode ocorrer sob as mais variadas formas, inclusive as mais sutis ${ }^{9}$. Sem pretensão de exaustividade, entre elas destacam-se as dez estratégias comuns:

\footnotetext{
${ }^{8}$ Frente a aportes de Morley e Habermas, María Menéndez (2009, p. 45) questiona se, a longo prazo, os efeitos da massificação da cultura informativa não acabam por produzir uma "ordem hierárquica" entre aqueles que podem fazer uso de sua capacidade argumentativa e crítica e aqueles que apenas "consomem" informações, o que também põe em xeque a suposta manifestação empírica de uma sociedade aberta, participativa e democrática. Aqueles que simplificam a comunicação e, eventualmente, produzem incapacidade de raciocínio situar-se-iam no topo da pirâmide comunicativa, ao tempo em que os que recebem apaticamente a comunicação, sofrendo uma regressão no poder de raciocinar, ficariam em sua base, lugar reservado para a simples aclamação.

${ }^{9}$ Stoppino (apud BOBBIO et al 2009, p. 935) esclarece: “A pode provocar um determinado comportamento de B sem manifestá-lo explicitamente; pode até esconder de B que ele deseja esse comportamento e sem que B se dê conta de que está se comportando segundo a vontade de A. Isto pode verificar-se, p. ex., em certos casos de propaganda camuflada. Este tipo de relação, habitualmente conhecido pelo nome de manipulação, entra, certamente, no âmbito do conceito de Poder".
} 
- a escolha tendenciosa de pautas (algumas vezes reforçada por uma descabida insistência ou um intempestivo resgate de temas específicos benéficos a candidatos prediletos ou prejudiciais a candidatos preteridos), manifestada também pelo que não se publica;

- o timing tendencioso, como nos casos de fatos perniciosos momentaneamente silenciados para virem à luz na véspera ou na própria data do pleito;

- a redução ou superexposição do tempo de cobertura, mais comum em meios audiovisuais, sujeitos à obrigação de conferir tratamento isonômico entre os participantes ${ }^{10}$;

- a omissão ou redução de destaque na divulgação de pesquisas de intenção de votos cujos resultados desagradem a linha editorial do veículo;

- o oferecimento de cobertura com visibilidade desproporcional, colocando em exagerada evidência a figura de um candidato em detrimento dos demais;

- a marginalização de atores, deixando-os de fora de rodadas de entrevistas ou negando-lhes convites para a participação em debates;

- a recusa ou a obstrução do acesso a espaços de propaganda comercializáveis, no caso da mídia impressa;

- a recusa deliberada ou a simulação de problemas técnicos como justificativa para a não reprodução total ou parcial de programas ou spots de propaganda referentes ao horário eleitoral gratuito;

- a desabilitação de ferramentas de comentários em notícias pontuais, a fim de bloquear a possibilidade de apresentação de desmentidos ou versões alternativas, por parte do público interativo;

- a realização de maquiagem informativa, conferindo às reportagens velados matizes ideológicos, a partir da construção elaborada de pontos de vista suspeitos ou que excluam uma ótica plural.

${ }^{10} \mathrm{O}$ nível de exposição que se confere à campanha eleitoral e aos assuntos políticos como um todo pode produzir benefícios a alguns de seus atores, por exemplo quando veículos simpáticos a ocupantes de cargos públicos em busca de reeleição privilegiam a cobertura de acontecimentos internacionais, com o objetivo de abafar crises ou problemas vivenciados na ordem interna. 
Há, como se nota, amplo espaço para a manipulação da opinião pública, desde a eleição do conjunto de temas a serem discutidos (agenda-setting) e da forma de aproximação e representação da realidade (enquadramento), até a escolha de palavras (seleção léxica) e imagens (seleção icônica) utilizadas, sendo claro que a arbitrariedade das escolhas é completamente ignorada pelos consumidores da informação (BARROS FILHO, 2003, p. 71).

Obviamente cada unidade no conjunto de estratégias não acarreta, per se, a configuração de abuso de poder, embora contribua cum grano salis para a quebra da competitividade da disputa. O reconhecimento da atuação nociva dos meios de comunicação social para fins de cassação de mandato ou anulação de pleito depende da constatação inequívoca de que os desdobramentos da cobertura jornalística comprometeram a lisura da contenda, para o que a gravidade das circunstâncias, como se verá, deverá ser objeto de análise profunda e cabal.

\subsection{A Extensão Hipotética dos Efeitos da Imprensa ${ }^{11}$}

Em comunidades vastas e complexas é impossível assimilar o mundo sem a mediatização, por isso os meios influem decisivamente na formação de opiniões e atitudes políticas. Esse poder, segundo Sánchez (1987), não é etéreo, pelo contrário, incide de modo concreto sobre os planos cognitivo, afetivo e comportamental da audiência, sua real extensão, contudo, é ainda uma incógnita para a comunidade científica. A partir de diferentes enfoques, existem estudos que lhes atribuem maior ou menor capacidade de influxo nos comportamentos humanos, sem, contanto, precisá-la, em virtude de impeditivos entendidos a seguir.

Em termos de desenvolvimento histórico, os efeitos dos meios foram objeto de pesquisas que podem ser abarcadas em três diferentes arquétipos: o modelo hipodérmico ${ }^{12}$ (ou de efeitos ilimitados); o modelo de efeitos mínimos (ou limitados); e o modelo de efeitos cumulativos (ou a longo prazo). O iter evolutivo - que não diz respeito a etapas cronologicamente sucessivas, mas coexis-

${ }^{11}$ O presente tópico - salvo breves alterações - consta de um estudo intitulado "Mídia, subjetividade e poder: influxos dos seminários políticos nas eleições presidenciais", realizado pelo autor com a colaboração de Gabriel Aranjues. A íntegra do trabalho pode ser conferida nos anais do III Seminário "Mídia, política e eleições”, promovido pelo PPG em Ciências Sociais da PUC-SP: [http://www.midiapoliticaeleicoes.wordpress.com].

${ }^{12} \mathrm{O}$ nome vem da capacidade de penetração das mensagens no interior dos indivíduos, à semelhança de agulhas de injeções subcutâneas. (ANDUIZA e BOSCH, 2012, p. 240).

Resenha Eleitoral (Florianópolis), v. 20, n. 2, p. 33-59, ago./der. 2016 
tentes (WOLF, 2004) - revela, em primeira passagem, a transição de uma perspectiva que via a mídia como quase onipotente para outra que reduziu brutalmente o alcance presumido de sua influência (MIGUEL, 2004). Posteriormente, os efeitos midiáticos seriam revalorizados com o surgimento de uma nova visão.

Em meados da década de 1930 desponta a ideia de que os meios de comunicação massiva surtiam efeitos poderosos ou ilimitados sobre o público. Nessa etapa, o receptor era considerado um elemento passivo e indefeso ${ }^{13}$, alvo de um emissor supostamente ativo e muito poderoso. Os efeitos da comunicação de massa seriam exercidos de maneira total, direta e irreversível sobre cada elemento do público pessoal e diretamente atingido pela mensagem (SERRANO, 2006). À falta de investigações empíricas, tais pressupostos eram corroborados pela observação e pela reflexão em torno dos efeitos que a propaganda bélica produzia tanto nas populações inimigas como nas aliadas durante a Primeira Guerra Mundial. (BEAUDOUX; D’ADAMO, 2015).

$\mathrm{Na}$ leitura de Wolf (2004), a corrente hipodérmica - que tem como expoentes nomes como Lasswell e Lipmann - ampara-se no conceito de sociedade de massas, e considera cada indivíduo como um "átomo isolado" que reage (também isoladamente) às sugestões da mídia. Assim, se as mensagens divulgadas conseguem alcançar os indivíduos que compõem a massa, a persuasão é facilmente "inoculada" em seu aparelho volitivo. $\mathrm{Ou}$ seja: "[...] se o alvo é atingido, a propaganda obtém o êxito que antecipadamente se estabeleceu", razão pela qual a teoria em questão foi chamada de bullet theory (teoria da bala) por Schramm (1971).

O modelo hipodérmico perderia espaço nas décadas seguintes, sobretudo em função da evolução metodológica com a aplicação da investigação empírica. Surgiria então o modelo dos efeitos mínimos, desenvolvido desde os trabalhos de Lazarsfeld e seus colaboradores (v. g. Berelson e McPhee). Segundo a proposta, os efeitos dos media não seriam diretos e tampouco inescapáveis em função de resistências potencialmente opos-

\footnotetext{
${ }^{13}$ Entre os cientistas políticos, Sartori (1965, p. 90-91) remete a tal entendimento: “Os estudos referentes à votação têm, com efeito, revelado um retrato muito obscuro do eleitor comum, tão obscuro que nos obriga a imaginar se o público em questão é mesmo algo mais do que uma audiência passiva. O cidadão comum nunca se interessa nem toma parte ativa no discurso político. Sua informação é, em verdade, mínima e sua percepção é distorcida e apriorística”.
} 
tas pelos grupos sociais às mensagens emitidas, máxime quando contrárias às convicções dos destinatários (SERRANO, 2006). Esses estudos propunham, em geral, que os grupos a que pertencem os indivíduos modelam suas percepções sobre a realidade política, funcionando como poderosas fontes de uma influência mediadora.

Fixava-se, em suma, a premissa de que a influição interpessoal é mais poderosa do que a dos veículos de comunicação, tendo em vista que, entre a informação fornecida pelos meios e sua recepção por parte de uma audiência, atuariam outras variáveis importantes, como a ação de líderes de opinião. (BEAUDOUX; D’ADAMO, 2015) ${ }^{14}$. Na dicção de Miguel (2004, p. 96):

Quanto ao impacto da mídia no comportamento dos eleitores, os estudos de Lazarsfeld e seus associados procuram minimizá-lo, fazendo sobressair a importância do meio social, que seria o motivador preponderante do voto e, por extensão, de todas as formas de adesão política. Mulheres e homens seguiriam um comportamento de tipo mimético, reproduzindo as atitudes e as opiniões de seus familiares, colegas de trabalho, vizinhos e amigos. O efeito da campanha eleitoral e, de forma mais ampla, de toda a informação veiculada pelos meios de comunicação fica reduzido à ativação e ao reforço de inclinações latentes. De acordo com uma das metáforas exploradas em The people's choice, seria uma situação análoga à de uma criança que coloca uma moeda sob uma folha de papel e em seguida passa sobre ela um lápis de cera: sem sua ação não surgiria nenhuma imagem, mas, ao mesmo tempo, ela não tem o poder de produzir qualquer imagem que não seja aquela que já se encontra gravada na face da moeda [...].

Ou seja, sem a presença de informação vinda de fora, a opinião não emergiria, mas a única opinião que ela é capaz de fazer brotar é aquela na qual o indivíduo já está predisposto, pela ação do meio social. Conteúdos que eventualmente contradigam tais disposições são em geral descartados, graças ao fenômeno da "dissonância cognitiva", isto é, graças à tendência que todas as pessoas têm de rechaçar informações incompatíveis com suas crenças.

Ao fim da década de 1960 inaugura-se uma terceira etapa, formada por uma série de estudos cujo denominador comum é a ideia de que

\footnotetext{
${ }^{14}$ Frise-se, porém, que os estudos não sustentavam que os media possuem pouco ou nenhum efeito de influência sobre a opinião pública. A rigor, tinha-se por alvo investigar as condições específicas sob as quais os meios de comunicação poderiam ter seus efeitos maximizados (SERRANO, 2006, p. 41).
}

Resenha Eleitoral (Florianópolis), v. 20, n. 2, p. 33-59, ago./de\%. 2016 
os efeitos de mero reforço e de leves mudanças evidenciados pelo estágio anterior ganham maior dimensão se considerados ao largo do tempo, em perspectiva cumulativa. Suas conclusões indicam que os meios têm uma influência poderosa, sutil e acumulada sobre as concepções do mundo social e político que os indivíduos desenvolvem e constroem ao longo de suas vidas. (BEAUDOUX; D’ADAMO, 2015). Entre essas formulações, destaca-se a teoria da agenda-setting, formulada por Shaw e McCombs e desenvolvida, entre outros, por Noelle-Neumann, Goffman e Iyengar. O modelo em tela emerge, entre outros fatores, de uma mudança de paradigma revelada pela percepção de que as comunicações não intervêm diretamente no comportamento explícito, tendendo, pelo contrário, a influir no modo como os destinatários das mensagens organizam a sua imagem sobre o ambiente que os envolve (ROBERTS apud WOLF, 2004, p. 60).

Sua hipótese central - para Weaver (1997) - resume-se na suposição de que a magnitude da ênfase e da cobertura midiática sobre diversos temas induz ao longo do tempo a que as pessoas considerem que esses temas se revistem de determinados graus de importância. Em suas pesquisas, Shaw e McCombs encontraram uma forte relação entre a hierarquia de temas estabelecidos pelos meios e a hierarquia temática expressada pelos votantes, o que sugeria uma influência dos meios sobre o eleitorado.

Na síntese de Weaver (1997), o processo de canalização midiática influi de maneira importante nos processos eleitorais, tanto na fixação do repertório temático de discussão como na definição da imagem dos candidatos. Ao fazer com que certos temas, certos candidatos e certas características suas sobressaiam ao resto, os meios contribuem de forma significativa para a construção de uma "percepção da realidade", da qual dependerá a decisão de votar ou não, e por quem fazê-lo, em caso afirmativo ${ }^{15}$.

\footnotetext{
${ }^{15} \mathrm{Na}$ análise de Anduiza e Bosch (2012, p. 243) os efeitos a longo prazo podem se dirigir a: criar um clima político propício, para que posteriormente se opere uma mudança de voto (p. ex., com a criação de uma clima de rejeição, mediante um bombardeio espetacularizado de escândalos); construir uma certa imagem dos candidatos que depois possa ser motivo de mudança de voto (mediante a potencialização determinados atributos - competência, liderança - ou debilidades - arrogância, desonestidade - de um futuro candidato); ou priorizar alguns acontecimentos sobre outros, de modo que os assuntos sobre os quais se centram a campanha sejam favoráveis para alguma das forças em disputa (p. ex., a partir da priorização de notícias sobre moradia ou educação, em detrimento da cobertura sobre segurança pública ou impostos).
} 
No campo do comportamento eleitoral, o oferecimento de conclusões inequívocas é dificultado pela presença de alguns elementos complicadores. Em primeiro lugar, o sigilo do voto, que impede a sua identificação e, por consequência, o estabelecimento de correlações entre sujeitos e resultados. Sendo impossível saber "quem votou em quem", elide-se a possibilidade de desenho de paralelos entre os alvos e suas condutas externadas nas urnas ${ }^{16}$. Além disso, impõe-se a lógica plausível de que os votos derivam de decisões complexas, sendo falaz colocar a mídia como único alimentador das decisões políticas.

Como pondera Bouza (1987), não cabe imputar exclusivamente à mídia fenômenos complexos que possuem fundamento em outros lugares da realidade. Logo, é preciso evitar "explicações monocausais", que prescindem da complexidade real dos fenômenos. Outrossim, impossível escapar da erronia inerente a todas as generalizações coletivas, isso torna para a área específica bastante pertinente o interrogante formulado por Charaudeau (2012, p. 22): “O que garante, em todo ato de comunicação, que haja correspondência - sem falar em coincidência - entre os efeitos que a instância de enunciação almeja produzir na instância de recepção e os efeitos realmente produzidos?”.

Com apoio em Bouza (1998), opina-se que, a despeito da existência de trabalhos muito bem fundamentados, não se pode afirmar contundentemente que os efeitos da mídia sobre o público já se encontram plenamente conhecidos e precisamente dimensionados. Sem embargo, o estado de conhecimento da questão permite afirmar que eles sem dúvida existem e se fazem presentes, havendo de ser mantidos como objeto de constantes cuidados e de permanente investigação.

\footnotetext{
${ }^{16}$ Nesse caminho, Anduiza e Bosch (2012, p. 74-75) ressaltam que o princípio do voto secreto tem repercussões metodológicas fundamentais no momento de estudar o comportamento eleitoral, quando se toma por análise o indivíduo: "Al garantizar que el voto se ejerza en libertad, sin temor a represálias, se impede relacionar el voto con las características individuales de los electores. Los votos son anónimos y por lo tanto no podemos relacionar, a partir de los resultados electorales, las características de los votantes con su orientación del voto".
} 


\subsection{A Gravidade das Circunstâncias no Uso Indevido dos Meios de Comunicação Social}

Em ações judiciais dirigidas à investigação de abuso de poder, a necessidade de exame da gravidade surge de alteração operada pela Lei de Ficha Limpa (Lei Complementar n⿳0 64/1990), de acordo com a qual o inciso XVI do art. 22 passou a prever que, para a configuração do ato abusivo, não será considerada a potencialidade de o fato alterar o resultado da eleição, mas somente a gravidade das circunstâncias que o caracterizam.

A inovação legislativa implicou em alterações axiológicas na estrutura dos ilícitos de abuso. O dispositivo teve como motor a superação de entendimento pacificado no Tribunal Superior Eleitoral, no sentido de que configuração de abuso, em qualquer modalidade, exige a demonstração da potencialidade de o fato desequilibrar o placar da eleição. Como se vê, o reconhecimento do abuso na ótica da Corte reclamava a valoração do elemento resultado.

A partir da reforma legal, a análise haverá de recair, também, sobre a conduta, que, agora, há de ser grave. Na esteira de Agra (2016, p.118-119) no modelo atual "a análise da gravidade não se detém ao resultado das eleições, perpassando todos os elementos que podem influir no transcurso normal e legítimo do processo eleitoral”.

López Zilio (2012) sublinha que a mudança de arranjo não afasta, em absoluto, a avaliação do impacto das condutas levadas a cabo sobre a integridade do certame, visto que o bem jurídico tutelado pelas ações de abuso de poder permanece inalterado, conforme o art. 14, $\$ 9^{\circ}$ do texto constitucional. Segue-se daí que "o efeito constitutivo do abuso de poder (em sua concepção genérica) permanece caracterizado pela potencialidade lesiva, a qual, agora, tem suas feições delineadas, no caso concreto, pela gravidade das circunstâncias do ilícito”. (LÓPEZ ZILIO, 2012, p. 200-201).

Assim, a gravidade das circunstâncias aparece como parâmetro para a avaliação dos impactos do ilícito sobre a legitimidade da disputa. Nesse panorama, "a potencialidade constitui pressuposto do reconhecimento do abuso do poder e consiste no exame da gravidade do ato ilícito de modo a comprometer a normalidade e a legitimidade das eleições." (TSE -AgR-RESPE 25.686.037/SP).

Frente a casos relacionados com o fenômeno em tela, não é dado ao intérprete desligar-se de sérias implicações de fundo. É de se ter em vis- 
ta, a todo instante, que o reconhecimento da incidência do abuso de poder conduz à aplicação de consequências drásticas, mormente a anulação de manifestações de soberania presumidamente válidas. À evidência de que os éditos de invalidação carregam em essência uma carga de contramaioria, é de suma importância que magistrados e cortes eleitorais avaliem com detenção e temperamento as nuanças dos casos concretos.

As condenações, certamente possíveis, são naturalmente medidas de exceção. Nessa linha, Coêlho (2012) vislumbra a gravidade das circunstâncias como um conceito jurídico aberto correlato às noções de proporcionalidade e razoabilidade, portanto conexo ao axioma da proibição do excesso. Disso decorrem os imperativos de adequação, necessidade e justa medida na cominação da pena de cassação de mandato. Em arremate, sustenta que "o ordenamento não admite seja configurado o abuso de poder por fato insignificante, sem relevo, desprovido de repercussão social”, e alerta (2012, p. 1):

A democracia pressupõe a prevalência da vontade da maioria, com respeito aos direitos da minoria. A banalização das cassações de mandato, com a reiterada interferência do Judiciário no resultado das eleições, pode gerar uma espécie de autocracia, o governo dos escolhidos pelos juízes, não pelo povo. O juízo de cassação de mandato por abuso de poder deve ser efetuado tão apenas quando existentes provas robustas de graves condutas atentatórias à normalidade e legitimidade do processo eleitoral e às regras eleitorais. Forçoso lembrar que o Direito em Roma era denominado de Jurisprudência, concebida como a ciência do Justo ou o direito do prudente.

À diferença do que se passa com os casos de abuso de poder político e econômico, as ações ligadas a desvios nos aparatos midiáticos não se embaraçam com dilemas probatórios, visto que as questões relativas à cobertura são (obviamente) públicas. Os obstáculos impostos são de ordem distinta: versam sobre a compreensão de mecânicas e reflexos inerentes ao universo comunicativo. Cobram-se, a rigor, leituras adequadas sobre os complexos meandros dos processos de comunicação, o que em parte explica a escassez de condenações nessa vereda. O campo escapa naturalmente à zona de conforto do jurista.

Interessante, pois, que se ofereçam parâmetros para a intelecção do que seja a gravidade em termos mais concretos, máxime porque o reque- 
rido cuidado com o trato desses problemas repele soluções assentadas sobre bases inespecíficas ou puramente deterministas. Como pondera Coêlho (2012, p. 02), o pressuposto da gravidade "deve ser fundamentado de forma detida e específica, e não de modo genérico, o que amplia a responsabilidade do julgador eleitoral". Disso decorre a intenção de oferecer indicadores que auxiliem o labor do hermeneuta, mediante o destaque de aspectos que sobrelevam as potencialidades da influência midiática sobre o comportamento do eleitor e sobre os destinos da disputa eleitoral.

Antes de elencá-los, convém advertir: se a potencialidade para a alteração dos resultados eleitorais já não é um elemento necessário para o reconhecimento de abuso, esse será mais evidente quando as circunstâncias demonstrem que aquela ilação é provável. Assim, faz-se importante uma análise de contexto: os impactos da cobertura parcial serão principalmente sentidos, por exemplo, em disputas para as quais as pesquisas de intenção de voto apontem situações de empate técnico. Também assim, é salutar que se perceba que o uso indevido dos meios de comunicação dificilmente decorre de atos isolados, sendo mais compatível com a ideia de uma cadeia de desenvolvimento produtora de um ambiente de agudo desequilíbrio informativo, com sérios prejuízos à faceta objetiva da liberdade de escolha eleitoral.

A literatura especializada fornece três grandes indicadores para o exame da parcialidade na cobertura informativa, são eles: os critérios de visibilidade, valência e enquadramento - parâmetros aplicados por alguns dos principais grupos de pesquisa de mídia no país, dentre os quais o Laboratório de Pesquisa em Comunicação Política e Opinião Pública (DOXA/ IUPERJ) e o Núcleo de Estudos em Mídia e Política (UNB).

A checagem de visibilidade tem o propósito de aferir o grau de evidência atribuído aos diversos candidatos, possibilitando o desnivelamento de vantagens derivadas da superexposição, assim como eventuais prejuízos provocados por um ostracismo político fundado na noção abstrata do "interesse jornalístico". Sobretudo em pleitos operados sobre grandes bases territoriais - caso de eleições nacionais, estaduais e em municípios de grande porte - é possível supor uma correlação natural entre o silêncio da imprensa e a baixa votação de candidatos marginalizados, uma vez que o eleitor, teoricamente, não chancela opções que (praticamente) desconhece.

A análise de valência permite o aprofundamento da análise, mediante a inserção de elementos qualitativos. Tem por objetivo otimizar os 
efeitos da visibilidade mediante a valoração do conteúdo tornado público; na prática as valências são atribuídas consoante o "potencial de impacto" transferido à candidatura. Segundo os termos definidos pelos pesquisadores do DOXA/IUPERJ, as matérias jornalísticas relativas à campanha eleitoral podem ser classificadas com:

(a) valência positiva, quando reproduzem promessas, programas de governo, declarações ou ataques a concorrentes, e que destacam bons resultados em pesquisas de intenção de votos;

(b) valência negativa, quando contemplam ressalvas, críticas ou ataques de concorrentes ou de terceiros aos candidatos, e que destacam desempenhos desfavoráveis em pesquisas eleitorais; e

(c) valência neutra, quando somente apresentam agendas de campanha ou espelham reportagens sem avaliação moral, política ou pessoal sobre os candidatos.

Em linhas gerais, o modelo de valência acompanha a quantidade de vezes em que o nome do candidato surge nos periódicos, assim como o valor atribuído ao concorrente em cada oportunidade. Um estudo pautado por tal método, além de medir a dimensão dos espaços conferidos a cada postulante, oferece ainda uma noção mais clara a respeito de quem o órgão de imprensa pode estar favorecendo. (NEVES, 2008, p. 12).

O estudo de enquadramento, por sua vez, possibilidade conhecer as posturas implicitamente adotadas pelos veículos, mediante a descoberta de suas linhas ou perspectivas. O conceito diz respeito aos padrões de apresentação, seleção e ênfase utilizados na organização dos relatos, funcionando como um modo de avaliação da relação entre a mídia e a política, a fim de compreender se (e quando) ela é usada como instrumento de poder ou como meio de informações objetivas e imparciais (NEVES, 2008, p. 11-12), ou seja, quando a mídia atua como ator ou como espaço político ${ }^{17}$.

Além dos aspectos retro mencionados, outras variáveis contribuem para a maximização dos efeitos da cobertura distorcida, aproximando a possibilidade de que a influência dos meios massivos possa haver distorcido o certame. Ao lado de circunstâncias exógenas relevantes, como o acirramento da disputa (situações de empate técnico) ou a existência de ajustes

\footnotetext{
${ }^{17}$ Para uma melhor compreensão da aplicação prática desses critérios, vide os estudos já mencionados de Alvim e Aranjues (2016), assim como a excelente obra de Flora Neves.
} 
entre candidatos e proprietários de veículos de comunicação, recomenda-se sejam observados:

- a natureza da(s) plataforma(s) midiática(s) utilizada(s) para a realização do ilícito ${ }^{18}$;

- o poder de penetração dos veículos envolvidos, medido pela tiragem (imprensa escrita), pelo volume diário de acessos (imprensa eletrônica) ou pelos níveis de audiência (rádio/televisão), e no qual igualmente influem detalhes como a existência de distribuição gratuita ou a amplitude do público-alvo a que se destinam;

- a existência de situações de monopólio ou quase-monopólio do campo informativo na região em que se desenvolve o pleito;

- o grau de diversidade interna (abertura de espaço para a divulgação de diferentes óticas ou pontos de vista) identificado no seio das mídias que tenham servido de instrumento para o ilícito;

${ }^{18}$ Entre os analistas, prevalece o entendimento de que a televisão é a plataforma que abriga maior potencial de influência sobre os cidadãos. Isso em razão de múltiplos fatores, cobrando destaque: a função da força persuasiva do vídeo; a maior abrangência do público; e a independência em relação ao fenômeno da exposição seletiva. Nada obstante, a mídia escrita possui atributos particulares compensatórios. Uma primeira vantagem sobre a oralidade refere-se à possibilidade de releitura, o que contribui para a qualificação dos processos mentais de reforço e memorização. É assente que a plataforma escrita, na medida em que favorece a mecânica cognitiva, incrementa a probabilidade de reprodução comportamental. Outrossim, o oferecimento de esquemas simplificadores como capas e headlines dotam os produtos do ramo impresso de grande aptidão para a fixação de conteúdos, em função da outorga de economia de raciocínio. Ao se condensar mensagens complexas em poucas palavras ou símbolos, reduz-se a complexidade dos discursos, facilitando as atividades de intelecção e retenção. Ao mesmo tempo, cria-se um modelo atrativo para outra espécie de público, formada por sujeitos que não dispõem de tempo ou interesse para a busca de informações analíticas, mais completas ou aprofundadas. Nesse diapasão, a exposição de primeira página surte enormes efeitos também entre não leitores ou leitores de ocasião. Além disso, recorde-se a existência dos chamados "leitores de banca de jornal", que de passagem por esses estabelecimentos dispensam parte de seu tempo para correr os olhos sobre os destaques jornalísticos do dia. Atualmente, é razoável supor a multiplicação da gama de leitores de ocasião, considerando-se a exposição de conteúdos possibilitada por novas formas de tecnologia, como redes sociais e aplicativos de mensagens instantâneas. Não por acaso, o compartilhamento eletrônico de reproduções de capas e manchetes sensacionalistas ou contundentes - por vezes repaginadas em memes - tornou-se uma prática corriqueira em períodos eleitorais. 
- o índice de diversidade externa apresentado pelo sistema de mídia específico (existência de órgãos concorrentes equilibrando o ambiente informativo e resgatando o pluralismo, com o oferecimento de perspectivas distintas);

- se a visibilidade da cobertura privilegiada foi maximizada pela repercussão de suas pautas em outros veículos, por exemplo, quando matérias de jornais ou revistas influenciam a agenda de programas de rádio e televisão;

- se no tratamento jornalístico foram identificadas práticas de falseamento, manipulação, crimes contra a honra ou ilícitos afins, inclusive reclamando a intervenção da Justiça Eleitoral;

- o índice de reiteração de matérias ${ }^{19}$ tendenciosas, com vistas ao correto dimensionamento do dano causado;

- o lapso de tempo no qual se desenvolve o jornalismo panfletário, com o propósito de sopesar a incidência de efeitos cumulativos sobre a audiência;

- o índice de credibilidade agregada à(s) plataforma(s) utilizada(s), proporcional ao prestígio que goze $(\mathrm{m})$ perante a população;

- a incidência de publicações de "pautas-bomba" (aptas a convencer eleitores indecisos ou a reverter preferências frágeis) de última hora, de modo a inviabilizar a apresentação de versões contrapostas ou mesmo a checagem de veracidade antes do início do processo de votação;

- a presença de aprofundamento investigativo direcionado ou de cegueira deliberada, a denotar perseguição ou favorecimento de sujeitos concorrentes;

- se as características do ambiente em que se desenvolvem as ações de comunicação permitem a reação dos atores prejudicados, atenuando os reflexos da cobertura privilegiada em razão de efeitos de contrapoder (v.g. o tempo de propaganda que os prejudicados possuem no horário eleitoral gratuito, o uso efetivo de direito de resposta ${ }^{20}$, a existência de frentes de apoio na cena

${ }^{19}$ Expediente conhecido como "matracagem", cf. Charaudeau (2012, p. 75).

${ }^{20}$ De todo modo, mensagens oriundas dos candidatos em propaganda ou direito de resposta não desfazem, integralmente, o impacto das notícias, sobretudo porque a credibilidade do organismo da imprensa, em virtude da presunção de objetividade, pode (e tende 
virtual, a presença de mídias alternativas ou de iniciativas de fact-checking com alcance razoável, etc.).

A rigor, a legitimidade eleitoral resiste a disparidades de tratamento no seio de um ou outro veículo midiático, desde que a confluência de diferentes óticas nutra o conjunto em que se desenvolvem as linhas da teia informativa. Como sugerido por Zippelius (2016, p. 414), a captação dos reais desejos e tendências de opinião dos cidadãos é mais provável de ser obtida "[...] quanto mais ampla for a oferta e a possibilidade de escolha entre diversas informações, apresentações de informações e tomadas de posição". No processo de formação das opiniões políticas, tal como nas eleições, "[...] só a possibilidade de escolha entre várias alternativas confere eficácia imediata a um 'elemento democrático..”.

A garantia de diversidade externa é, portanto, o aspecto mais relevante. No fundo, o que o sistema de integridade não absorve - para além de campanhas de manipulação ou desinformação - é a negação virtual ou a atrofia do pluralismo dos pontos de vista. A axiologia eleitoral se orienta pelos valores da liberdade e da igualdade e, nesse caminho, impõe o desenvolvimento disputas livres de um jornalismo assimétrico hábil à quebra da igualdade de oportunidades entre os competidores ${ }^{21}$ e ao desvio da autêntica vontade pelo condicionamento do ambiente em que se forma a opinião eleitoral ${ }^{22}$.

a) ser maior do que a competidor político, o que minimiza os efeitos dos discursos de refutação.

${ }^{21}$ A vantagem obtida pelo ator que goza da preferência da mídia e o déficit de competitividade dela decorrente são muito bem ilustrados por Giovanni Sartori, como recorda Sánchéz Muñoz (2007, p. 80): pela ótica do mestre italiano, o candidato apoiado pela imprensa é como um enxadrista que joga com duas rainhas.

${ }^{22}$ Sánchez Muñoz (2007, p. 43) bem observa que a escolha do eleitor se concebe como o resultado de um processo de comunicação entre os membros da comunidade política e, em consequência, quanto mais livre seja aquele processo, mais livre será a própria eleição. $\mathrm{O}$ autor espanhol é sagaz em notar que a liberdade do processo de formação da escolha pode ser ameaçada não apenas no intuitivo plano individual, quando um eleitor se encontra vítima de pressões ou coações que o obrigam a optar por uma das alternativas sem que isso seja fruto de seu arbítrio livre, mas ainda no plano coletivo, quando o processo de comunicação prévio à votação não é um processo no qual as diferentes alternativas tenham as mesmas oportunidades de fazerem visíveis perante os eleitores, em função de que algumas delas gozam de vantagens ilegítimas. Nesse último caso, ainda que do ponto de vista subjetivo a decisão dos eleitores siga sendo livre, pelo ângulo objetivo o processo de 


\section{Considerações Finais}

Com a finalidade de aprofundar o estado de conhecimento a respeito dos influxos da imprensa nos destinos do processo eleitoral, procedeu-se ao estudo de questões relativas ao fenômeno do uso indevido dos meios de comunicação social, primeiramente direcionado à produção de uma aproximação teórica sobre a origem e os fundamentos da capacidade de persuasão pública incorporada pela mídia. Nessa tarefa, consignou-se que os órgãos da imprensa abrigam um poder de tipo ideológico, eficaz na medida em que o comportamento político responde à atmosfera informacional em que estão imersos os indivíduos.

Procurou-se igualmente demonstrar que a cobertura jornalística opera reflexos concretos sobre o comportamento eleitoral, pelo que deve ser objeto de rigorosa tutela normativa e efetivo controle jurisdicional, com vistas à preservação do índice de integridade dos pleitos. Sem a configuração de um estatuto protetivo adequado - e sem a presença de uma administração de justiça eficiente - os desvios na atividade midiática podem ocasionar prejuízos ao processo, limitando a liberdade de escolha do eleitor (em função de um condicionamento ambiental) e minando a isonomia entre os candidatos, pressuposto axiológico da competição eleitoral.

Trabalhou-se ainda para elencar estratégias que denotam a presença de parcialidade na cobertura, com a intenção de facilitar a sua identificação, assim como para arrolar parâmetros válidos para a aferição da gravidade de suas circunstâncias, requisito indispensável para a prolação de decisões seguras em sede de ações eleitorais em que se discutem casos de abuso de poder. No particular, ressaltou-se a relevância da pluralidade externa como fator de garantia da qualidade informativa da cobertura eleitoral.

A campanha eleitoral constitui, sobretudo, um procedimento dialético marcado pelo choque antagônico de fatos, projetos, opiniões e pontos de vista. Quanto mais igual for a visibilidade que se lhe confere, menores serão os efeitos da comunicação distorcida e maiores os índices de integridade do processo. Em última instância, o sistema de proteção da autenticidade eleitoral deve tender à garantia do máximo pluralismo informativo. Nesse passo, assenta-se o entendimento de que a noção de legitimida-

formação da vontade é afetado de alguma maneira pelo que chama de "condicionamentos ambientais". 
de eleitoral é, em princípio, resiliente a práticas de jornalismo tendencioso, desde que no plano das comunicações a perspectiva plural não se encontre substancialmente diminuída ou virtualmente açodada.

\section{Referências}

ALVIM, Frederico Franco. Curso de Direito Eleitoral. $2^{\underline{a}}$ ed. Curitiba: Juruá, 2016.

. ARANJUES, Gabriel Silva. Mídia, subjetividade e poder: influxos dos seminários políticos nas eleições presidenciais. Anais do III Seminário "Mídia, política e eleições", promovido pelo PPG em Ciências Sociais da PUC-SP. Disponível em: <http://www.midiapoliticaeleicoes.wordpress. com>. Acesso em: 29 dez. 2016.

ANDRADE SÁNCHEZ, Eduardo. Introducción a la Ciencia Política. Ciudad de México: Oxford Press, 2013.

ANDUIZA, Eva; BOSCH, Agustí. Comportamiento político y electoral. Barcelona: Ariel, 2012.

AZEVEDO, Fernando Antônio. Mídia e democracia no Brasil: relações entre o sistema de mídia e o sistema político. Opinião Pública, vol. 12, no 1, abril/ maio, 2006, p. 88-113.

BARROS FILHO, Clóvis de. Ética na comunicação. 4르. ed. São Paulo: Summus Editorial, 2003.

BEAUDOUX, Virginia García; D’ADAMO, Orlando. "Efectos de los medios de comunicación (mass media research)". In: MARTÍNEZ, Ismael Crespo; D’ADAMO, Orlando; BEAUDOUX, Virginia García; RODRÍGUEZ, Alberto Mora (coords.). Diccionario enciclopédico de comunicación política. Madrid: Centro de Estudios Políticos y Constitucionales, 2015, p. 149-151.

BIDART CAMPOS, José German. E1 poder. Buenos Aires: Ediar, 1985. BIM, Eduardo Fortunato. O polimorfismo do abuso de poder no processo eleitoral: o mito de Proteu. Revista do TRE-RS. Porto Alegre. v. 8. $\mathrm{n}^{\mathrm{o}}$ 17, jul./dez. 2003.

BOBBIO, Norberto. Teoria geral da política. A filosofia política e as lições dos clássicos. Rio de Janeiro: Campus, 2000. . MATTEUCCI, Nicola; PASQUINO, Gianfranco. Dicionário de política. 2 vol. 13르 ed. Brasília: Editora UNB, 2010. 
BOUZA, Fermín. La influencia política de los médios de comunicación: mitos y certezas del nuevo mundo. In: DELGADO, Juan Benavides (org.). Madrid: Fundación General de la Universidad Complutense de Madrid, 1998, pp. 237-52.

CASTILLO SÁNCHEZ, Guillermo. La comunicación y la formación de la actitud política. Comunicación y medios, n⿳ำ 6, diciembre 1987, p. 87-96. CHARAUDEAU, Patrick. Discurso das mídias. $2^{\underline{a}}$ ed. São Paulo: Contexto, 2012.

COÊLHO, Marcus Vinicius Furtado. A gravidade das circunstâncias no abuso de poder eleitoral. Disponível em: <http://www.tre-rj.gov.br/eje/ gecoi_arquivos/arq_071881.pdf>. Acesso em: 29 dez.2016.

CORREA FREITAS, Ruben. Derecho Constitucional contemporâneo. Tomo I. Montevideo: FCU, 2007.

FAYT, Carlos Santiago. Derecho Político. Tomo II. 12 ed. Buenos Aires: La Ley, 2009.

FEINMANN, José Pablo. Filosofía política del poder mediático. Buenos Aires: Planeta, 2013.

FERNÁNDEZ RUIZ, Jorge. Tratado de Derecho Electoral. Ciudad de México: Porrúa, 2010.

FIGUEIREDO, Hernán R. Gonçalves. Manual de Derecho Electoral: principios y reglas. Teoría y práctica del régimen electoral y de los partidos políticos. Buenos Aires: Di Lalla, 2013.

GALVIS GAITÁN, Fernando. Manual de Ciencia Política. Bogotá: Temis, 2005.

GOFFMAN, Erving. Os quadros da experiência social: uma perspectiva de análise. Petrópolis: Vozes, 2006.

GOMES, José Jairo. Direito Eleitoral. 5ae ed. Belo Horizonte: Del Rey, 2009. HERMET, Guy; BADIE, Bertrand; BIRNBAUM, Pierre; BRAUD, Philippe. Dicionário de Ciência Política e das instituições políticas. Lisboa: Escolar Editora, 2014.

IYENGAR, Shanto. "The accessibility bias in politics. Television news and public opinion". International Journal of Public Opinion Research, 2, $1-15$. 
JORGE, Flávio Cheim; RODRIGUES, Marcelo Abelha. Manual de Direito Eleitoral. São Paulo: Saraiva, 2014.

LAZARSFELD, Paul; BERELSON, Bernard; McPhee, Wiliam. Voting: a study of opinion formation in a presidential campaign. Chicago: University of Chicago, 1986.

LIPPMANN, Walter. Opinião pública. Petrópolis: Vozes, 2008.

MACCOMBS, Maxwell. Setting the Agenda: the mass media and public opinion. Cambridge: Polity Press, 2006.

MACCOMBS, Maxwell; SHAW, Donald. "The agenda-setting function of mass media”. Public Opinion Quaterly, 36 (2), 176-187.

MENÉNDEZ, María Cristina. Política y medios en la era de la información. Buenos Aires: La Crujía, 2009.

MIÈGE, Bernard. A sociedade tecida pela comunicação. Técnicas da informação e da comunicação entre inovação e enraizamento social. São Paulo: Paulus, 2009.

MIGUEL, Luis Felipe. Mídia e vínculo eleitoral: a literatura internacional e o caso brasileiro. Opinião Pública, vol. X, nº 1, maio de 2004, p. 91-111.

NEVES, Flora. Telejornalismo e poder nas eleições presidenciais. São Paulo: Summus, 2008.

NOELLE-NEUMANN, Elisabeth. "Turbulences in the climate of opinion". Public Opinion Quaterly, 41 (2), 143-158.

NORRIS, Pippa. Why electoral integrity matters. Oxford: Oxford Press (edição eletrônica kindle), 2013.

OLIVOS CAMPOS, José René. Ciencia Política. Ciudad de México: UNAM, 2012.

RIBEIRO, Fávila. Abuso de poder no Direito Eleitoral. $3^{\underline{a}}$ ed. Rio de Janeiro: Forense, 2000.

RODRIGUES, Marcelo Abelha; JORGE, Flávio Cheim. Manual de Direito Eleitoral. São Paulo: RT, 2014.

ROUSSEAU, Jean Jacques. O contrato social. São Paulo: Editora Folha de São Paulo, 2010.

SÁNCHEZ MUÑOZ, Óscar. La igualdad de oportunidades en las competiciones electorales. Madrid: Centro de Estudios Constitucionales, 2007. 
SARTORI, Giovanni. La democracia en treinta lecciones. Madrid: Taurus, 2009.

SERRANO, Estrela. Jornalismo político em Portugal. A cobertura de eleições presidenciais na imprensa e na televisão (1976-2001). Lisboa: Instituto Politécnico de Lisboa, 2006.

STOPPINO, Mario. Poder. In: BOBBIO, Norberto; MATTEUCCI, Nicola; PASQUINO, Gianfranco. Dicionário de política. $13^{a} \mathrm{ed}$. Brasília: UNB, 2009, p. 933-943.

URIARTE, Edurne. Introducción a la Ciencia Política. La política en las sociedades democráticas. $3^{\underline{a}}$ ed. Madrid: Tecnos, 2010.

VELLOSO, Carlos Mário da Silva; AGRA, Walber de Moura. Elementos de Direito Eleitoral. 2ª ed. São Paulo: Saraiva, 2012.

VILAS, Carlos María. El poder y la política: el contrapunto entre razón y emoción. Buenos Aires: Editorial Biblios, 2013.

WEAVER, David H. Canalización mediática (agenda-setting) y elecciones en Estados Unidos. Publicaciones UCM, 1997, p. 229-241.

WEBER, Max. O direito na economia e na sociedade. São Paulo: Ícone, 2011.

WOLF, Mauro. Teorias da comunicação. $8^{\underline{a}}$ ed. Lisboa: Presença, 1999.

ZILIO, Rodrigo López. Potencialidade, gravidade e proporcionalidade: uma análise do art. 22, XVI, da Lei Complementar nº 64/90. Revista Brasileira de Direito Eleitoral, no 6, jan./jun. 2012.

ZIPPELIUS, Reinhold. Teoria geral do Estado e Ciência Política. São Paulo: Saraiva, 2016.

Frederico Franco Alvim - Doutor em Ciências Jurídicas e Sociais (UMSA). Mestrando em Direito (UNIMEP). Taxista CAPES/PROSUP. Especialista em Direito Eleitoral (UFG /AVM). Analista Judiciário do Tribunal Regional Eleitoral de São Paulo. Professor de Direito Eleitoral. Membro fundador da Academia Brasileira de Direito Eleitoral. Autor. 